\title{
Metal-Free Reduction of Phosphine Oxides Using Polymethylhydrosiloxane
}

\author{
Emmanuel Nicolas ${ }^{1}$, Antonella Guerriero ${ }^{2}$, Volodymyr Lyaskovskyy ${ }^{1}$, Maurizio Peruzzini ${ }^{2}$, \\ Koop Lammertsma ${ }^{1}$, Luca Gonsalvi ${ }^{2, *}$ and J. Chris Slootweg ${ }^{1,3, *}$ \\ 1 Department of Chemistry and Pharmaceutical Sciences, Vrije Universiteit Amsterdam (VU), \\ De Boelelaan 1083, 1081 HV Amsterdam, The Netherlands; emmanuel.nicolas@cea.fr (E.N.); \\ v.lyaskovskyy@vu.nl (V.L.); k.lammertsma@vu.nl (K.L.) \\ 2 Consiglio Nazionale delle Ricerche, Istituto di Chimica dei Composti Organometallici (CNR-ICCOM), \\ Via Madonna del Piano 10, 50019 Sesto Fiorentino, Italy; antonella.guerriero@iccom.cnr.it (A.G.); \\ maurizio.peruzzini@iccom.cnr.it (M.P.) \\ 3 Van 't Hoff Institute for Molecular Sciences, University of Amsterdam (UvA), Science Park 904, \\ 1098 XH Amsterdam, the Netherlands \\ * Correspondences: l.gonsalvi@iccom.cnr.it (L.G.); j.c.slootweg@vu.nl (J.C.S.); \\ Tel.: +39-055-522-5251 (L.G.); +31-20-598-7482 (J.C.S.)
}

Academic Editors: Lee J. Higham and Duncan H. Gregory

Received: 9 September 2016; Accepted: 1 November 2016; Published: 3 November 2016

\begin{abstract}
A simple protocol is presented here for the use of inexpensive polymethylhydrosiloxane (PMHS), a waste product of the silicon industry, as stoichiometric reducing agent for phosphine oxides to phosphines, a highly desirable reaction to recover P-based ligands from their spent form. The reactions were studied by screening parameters, such as substrate to reductant ratio, temperature and reaction time, achieving good conversions and selectivities.
\end{abstract}

Keywords: phosphine oxides; reduction; PMHS; sustainable chemistry

\section{Introduction}

Nowadays chemical sustainability has to be thoroughly considered in the design and realization of new processes and in the upgrading of old technology to new solutions. Among the various aspects, recycling of spent reagents or by-products, cost-effectiveness and improved E-factor [1] can add up to a more efficient and sustainable approach to chemical production, which is highly desirable especially when scale up from lab to plant scale is envisaged.

Phosphorus is now considered as an endangered element, with dwindling feedstock resources, two thirds of which located in Northern Africa, setting the stage for political unpredictability. In order to reduce our dependency for this life-essential element, it is thus essential to envisage safe, cheap an efficient routes for phosphorus recovery and reuse [2].

Phosphines are ubiquitous compounds in the chemical armory. They are found in countless applications both in academia and in industry, and when used as ancillary ligands for transition metal catalysts, they can impart properties allowing for high activities and selectivities of homogeneous catalytic processes, which could not be achieved otherwise $[3,4]$. One of the major problems with tertiary phosphines is, however, their general sensitivity to oxidation from $\mathrm{P}(\mathrm{III})$ to $\mathrm{P}(\mathrm{V})$, i.e., phosphine oxides. Phosphine oxides are also generated in large quantities as by-products of industrial scale applications such as the Wittig reaction [5] or in water-phase catalysis [6]. Even though many chemical methods that reduce $\mathrm{R}_{3} \mathrm{P}=\mathrm{O}$ to $\mathrm{R}_{3} \mathrm{P}$ are known in the literature [7], they usually need harsh reaction conditions, stoichiometric amounts of toxic or dangerous reagents and are often scarcely functional-group tolerant. Limited solubility of phosphine oxides and cumbersome separation of products from reagents are often discouraging for widespread applications. 
The most commonly used reductants for $\mathrm{P}=\mathrm{O}$ bonds include silanes, boranes and metal hydrides based on Al and Ca [7]. Among silanes, as early as 1964, Fritzsche, et al. [8-10] reported that phenylsilane, diphenylsilane, triphenylsilane and PMHS (polymethylhydrosiloxane, Scheme 1) could be used in excess stoichiometry to reduce alkyl, aryl phosphine oxides and dihydrophosphole oxides (Scheme 2). In this early study, a strong dependence of yields on the substitution on the aryl groups, hence to the electron density at the phosphorus atom, was observed. On the other hand, the nature of the silane did not significantly influence the yield, although the use of PMHS gave lower selectivity to the desired products in case of less robust substrates, due to the P-C bond cleavage. A study by Keglevich, et al. demonstrated the efficient use of PMHS for the reduction of a number of triphenylphosphine oxide derivatives, with reaction times ranging from 7 to $16 \mathrm{~h}$ [11]. An improved protocol was obtained using trichlorosilane (1 equiv. to substrate), reaching yields up to $98 \%$ for the reduction of triphenylphosphine oxide. The use of triethylamine as additive proved to be highly beneficial for the reduction of trialkylphosphine oxides. For instance, tri( $n$-butyl)phosphine oxide was reduced using $\mathrm{HSiCl}_{3} / \mathrm{NEt}_{3}$ (1:1) reaching $92 \%$ yield [12].<smiles>CC(C)(O[Si](C)(C)C)[Si](C)(C)O[Si](C)(C)C</smiles>

Scheme 1. General structure of PMHS (polymethylhydrosiloxane).

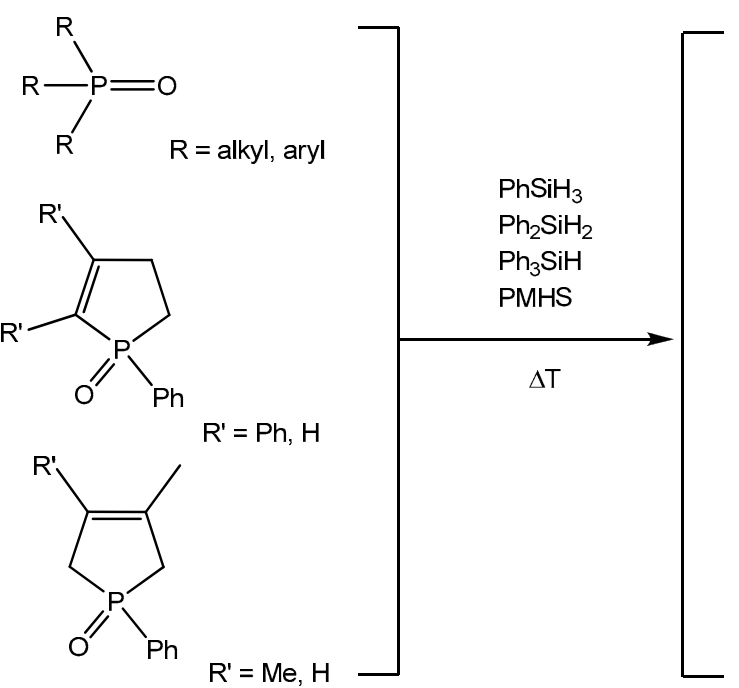<smiles>[R]P[R]P</smiles>
$33 \%-98 \%$<smiles>[R]C1=C([R])P(P)CC1</smiles>

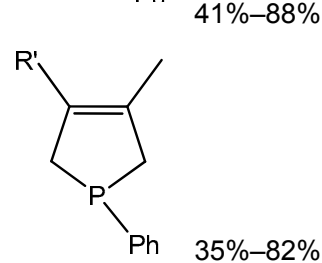

Scheme 2. Reduction of acyclic phosphine oxides and cyclic hydrophosphole oxides with hydrosilanes [8].

In order to minimize the amount of silanes needed to achieve good conversions, a number of research groups investigated the use of metal catalysts for $\mathrm{P}=\mathrm{O}$ bond reduction with this reagent. Titanium(IV) was employed to reduce alkyl- and aryldiphenylphosphine oxides under mild conditions using $(\mathrm{EtO})_{3} \mathrm{SiH}$ [13]. A major drawback in the use of PMHS instead of $(\mathrm{EtO})_{3} \mathrm{SiH}$ was that one equivalent of Ti(IV) was necessary to achieve meaningful conversions (Scheme 3), and no reaction was observed in the absence of the catalyst.

Other metals were tested in combination with tetramethyldisiloxane (TMDS) as an alternative to PMHS, namely In(III) [14] and Cu(II) [15]. Whereas the former method suffered from limited scope due to poor functional group tolerance leading to unselective reactions, in the latter case amounts of $\mathrm{Cu}$ salts up to $10 \%$ were needed. Brønsted acid-catalysed reductions with PMHS were also demonstrated, however modest conversions were obtained compared to $(\mathrm{EtO})_{3} \mathrm{SiH}$ [16]. Using more reactive silanes proved to be beneficial and excellent conversions and yields were obtained by the group of Werner using hexyl silane as the reducing agent and triflic acid as the catalyst [17]. 


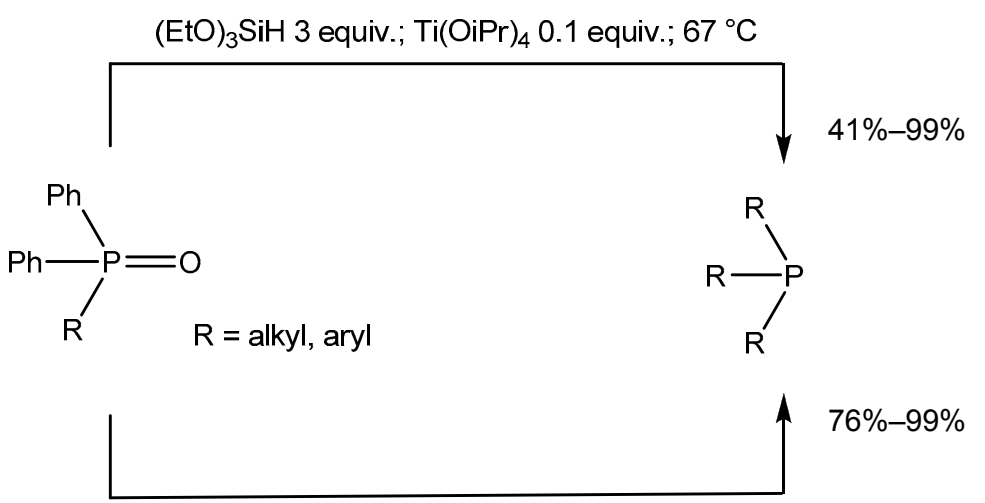

PMHS 10 equiv.; $\mathrm{Ti}(\mathrm{OiPr})_{4} 0.1$ equiv.; $67^{\circ} \mathrm{C}$

Scheme 3. Ti-catalysed phosphine oxide reduction using (EtO) ${ }_{3} \mathrm{SiH}$ or PHMS [13].

In the context of sustainability, we reasoned that an improved protocol enabling the (metal-free) efficient use of PMHS, a waste product of the silicon industry that is cheap and widely available, could be of interest. We present here results on the reduction of a small library of industrially-relevant phosphine oxides using PHMS in modest stoichiometric excess, with good results for activity and selectivity, where we first benchmark our experimental set-up with the results of Keglevich, et al. [11] by studying the triphenylphosphine oxide reduction under related conditions, then study the kinetics of this deoxygenation reaction, and subsequently extend the scope to trialkylphosphine oxides. Examples of water-soluble phosphine oxides reduction with PHMS, a case often neglected in the literature, are also shown for the first time.

\section{Results}

In order to investigate the scope of PMHS reduction of phosphine oxides to phosphines, we thus chose as target substrates triphenylphosphine oxide (TPPO, 1), tri(tert-butyl)phosphine oxide (2), tricyclohexyl phosphine oxides (3), tri(n-octyl)phosphine oxide (TOPO, 4), 3-methyl-1-phenyl-2phospholene-1-oxide (5), 3-methyl-1-phenylphospholane-1-oxide (6) as examples of aryl and alkyl, linear and cyclic phosphine oxides. 1,3,5-Triaza-7-phosphaadamantane phosphine oxide (PTA(O), 7) and the corresponding $N$-methyl analogue $\mathrm{mPTA}(\mathrm{O})(8)$ were chosen as examples of neutral and charged water soluble cage-like substrates (Scheme 4). PTA and mPTA oxidation at the P atom often occurs as side reaction for transition metal catalysed processes in water using PTA-based catalysts and are linked to catalyst deactivation $[18,19]$, hence it would be of interest to find a selective recycling protocol for these expensive, tailor-made ligands.<smiles>O=P(c1ccccc1)(c1ccccc1)c1ccccc1</smiles><smiles>CCP(=O)(CC(C)(C)C)C(C)(C)C</smiles><smiles>O=P(Cl)(Cl)[Ge]</smiles>

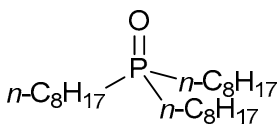

triphenylphosphine oxide 1

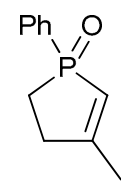

5 tri(tert-butyl)phosphine oxide 2

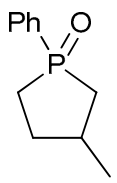

6 tricyclohexylphosphine oxide 3<smiles>O=P12CN3CN(CN(C3)C1)C2</smiles><smiles>O[Te][TeH]</smiles>

tri(n-octyl)phosphine oxide 4

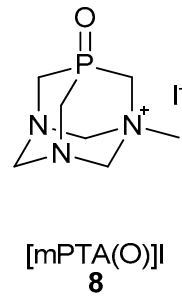

Scheme 4. Target substrates for $\mathrm{P}=\mathrm{O}$ bond reduction using PMHS. 
The reduction reactions were carried out as described in the Materials and Methods Section and the results are summarized in Table 1 . Substrate 1 was chosen as benchmark using 5 equiv. of PMHS at $250{ }^{\circ} \mathrm{C}$ for $0.5 \mathrm{~h}$ for initial testing that yielded $\mathrm{Ph}_{3} \mathrm{P}$ in $24 \%$ yield (Entry 1 ).

Table 1. Screening of different substrate/PMHS (polymethylhydrosiloxane) ratios, temperatures and reaction times ${ }^{1}$.

\begin{tabular}{|c|c|c|c|c|c|}
\hline Entry & Substrate & PMHS (equiv.) & $T\left({ }^{\circ} \mathrm{C}\right)$ & $t$ (h) & Yield $(\%)^{2}$ \\
\hline 1 & 1 & 5 & 250 & 0.5 & 24 \\
\hline 2 & 1 & 5 & 250 & 1 & 45 \\
\hline 3 & 1 & 5 & 250 & 1.5 & $86(84)$ \\
\hline 4 & 1 & 15 & 250 & 1 & 90 \\
\hline 5 & 1 & 5 & 200 & 24 & 90 \\
\hline 6 & 1 & 5 & 220 & 24 & 100 \\
\hline 7 & 2 & 5 & 220 & 1 & 100 \\
\hline 8 & 3 & 5 & 250 & 6 & 0 \\
\hline 9 & 3 & 10 & 200 & 3 & 7 \\
\hline 10 & 3 & 10 & 200 & 6 & $<1$ * \\
\hline 11 & 3 & 15 & 200 & 6 & 10 \\
\hline 12 & 3 & 15 & 250 & 2 & 20 \\
\hline 13 & 3 & 15 & 250 & 6 & 5 \\
\hline 14 & 3 & 15 & 250 & 7 & $<1$ * \\
\hline 15 & 4 & 10 & 200 & 3 & 4 \\
\hline 16 & 4 & 10 & 200 & 6 & 33 \\
\hline 17 & 4 & 10 & 250 & 3 & 12 \\
\hline 18 & 4 & 10 & 250 & 6 & 53 \\
\hline 19 & 4 & 15 & 200 & 3 & 30 \\
\hline 20 & 4 & 15 & 200 & 7 & 87 \\
\hline 21 & 4 & 15 & 250 & 3 & 13 \\
\hline 22 & 4 & 15 & 250 & 7 & 82 \\
\hline 23 & 5 & 5 & 250 & 1 & 100 \\
\hline 24 & 6 & 5 & 250 & 1 & 100 \\
\hline 25 & 6 & 5 & 220 & 1 & 100 \\
\hline 26 & 7 & 5 & 220 & 1 & $83(78)$ \\
\hline 27 & 8 & 10 & 250 & 1 & $<1 *$ \\
\hline 28 & 8 & 15 & 200 & 6 & $<1$ \\
\hline 29 & 8 & 15 & 200 & 20 & $<1^{*}$ \\
\hline
\end{tabular}

${ }^{1}$ Conditions: $1.0 \mathrm{~g}$ of substrate and PMHS were heated in a Schlenk flask under $\mathrm{N}_{2}$. Equiv. of PMHS measured as the ratio of $\mathrm{Si}-\mathrm{H}$ to $\mathrm{P}=\mathrm{O}$ bonds; ${ }^{2}$ Yields based on NMR relative integration (isolated yields in brackets); * Product decomposition occurred.

The effect of substrate to PMHS ratio was then studied. In the case of $\mathbf{1}$, increasing the amount of PMHS from 5 to 15 equiv. at $250{ }^{\circ} \mathrm{C}$ increased the conversion after $1 \mathrm{~h}$ significantly, from $45 \%$ to 90\% (Entries 2 and 4), which under related conditions was also found by Fritzsche, et al. [8-10] and Keglevich, et al. [11].

A kinetic study was then performed on the reduction of $\mathbf{1}$ using 5 equiv. of PMHS at $250{ }^{\circ} \mathrm{C}$, by sampling the reaction every $30 \mathrm{~min}$ (Entries 1-3). The kinetic profile shown in Figure 1 demonstrated that the reaction proceeds essentially with a zero-order in substrate. Subsequently, the effect of temperature was studied. As expected, a longer reaction time was needed to reach significant conversions when lowering the reaction temperature. Selective reduction of $\mathbf{1}$ occurred in presence of 5 equiv. of PMHS at both 200 and $220^{\circ} \mathrm{C}$ after $24 \mathrm{~h}$ with conversions of $90 \%$ and $100 \%$, respectively (Entries 5 and 6). 


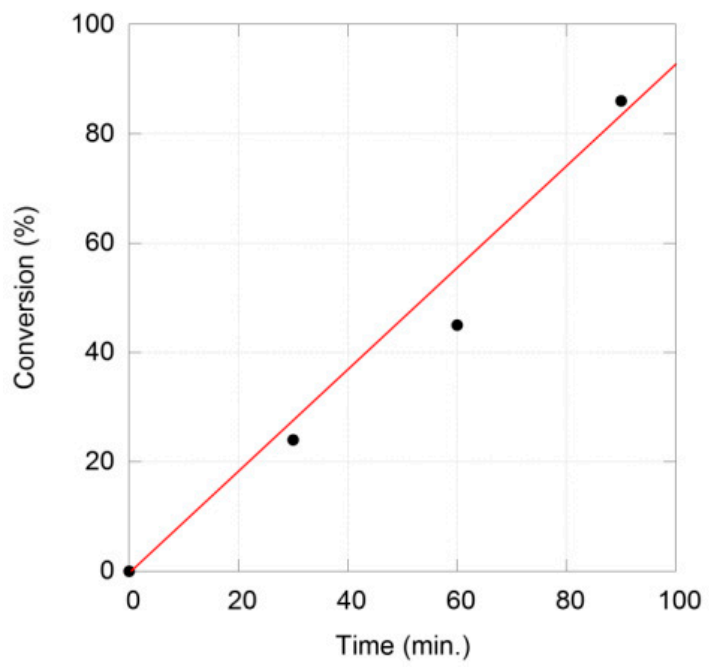

Figure 1. Kinetic profile of the reaction of $\mathbf{1}$ with PHMS (polymethylhydrosiloxane, 5 equiv.) at $250{ }^{\circ} \mathrm{C}$.

For trialkyl phosphine oxides, in the case of 2 , complete conversion was achieved after $1 \mathrm{~h}$ using 5 equiv. of PMHS at $220^{\circ} \mathrm{C}$ (Entry 7). Compound 3 proved to be more troublesome. The highest conversion $(20 \%)$ was obtained running the reaction for $2 \mathrm{~h}$ at $250{ }^{\circ} \mathrm{C}$ using 15 equiv. of PMHS (Entry 12). Attempts to use lower amounts of reductant (Entries 9 and 10), lower temperatures (Entry 11) or longer reaction times (Entries 13 and 14) led invariably to lower yields of tricyclohexyl phosphine, likely due to poor product stability under the harsh reaction conditions causing decomposition.

Better results were obtained using 4, a long-chain (n-octyl) alkyl phosphine oxide often used as stabiliser for metal nanoparticle synthesis [20], or as extraction agent, especially for uranium [21]. After optimisation of the reaction conditions (Entries 15-22), the highest conversion (87\%) was obtained with 15 equiv. PHMS at $220^{\circ} \mathrm{C}$ after $7 \mathrm{~h}$ (Entry 20).

In the case of cyclic substrates, such as phospholene oxide 5 and phospholane oxide 6 that both are relevant in catalytic Wittig reactions [22,23], excellent results were obtained using only 5 equiv. of PHMS at either 220 or $250{ }^{\circ} \mathrm{C}$ using short $(1 \mathrm{~h}$ ) reaction times (Entries 23-25).

Finally, in the case of water-soluble phosphine oxides, good results were obtained for substrate 7 reaching $83 \%$ conversion under standard test conditions, representing the first affordable method for PTA $(\mathrm{O})$ reduction to PTA (Entry 26). The charged $N$-methylated analogue 8, however, resulted either in decomposition or no reaction was observed (Entries 27-29).

Isolated yields were obtained for the reduction of $\mathbf{1}$ and $\mathbf{7}$ and were generally in good agreement with the NMR yields (see the Materials and Methods Section and Table 1). Filtration of the dichloromethane solutions over silica allowed the removal of most of the silicon-based byproducts and unreacted reagents, giving NMR pure samples of the corresponding phosphines after a simple workup.

\section{Discussion}

Several interesting observations were obtained from the results described above. Our protocol works with good efficiency in the reduction of triphenylphosphine oxide (1), and fine-tuning of the reaction conditions allowed for high yields in triphenylphosphine at $220^{\circ} \mathrm{C}$ when the reaction is carried out for $24 \mathrm{~h}$ using only 5 equiv. of PMHS. This achievement was possible due to the stability of the product, allowing the use of relatively high temperatures without causing the formation of side products. This pre-requisite was confirmed for other phosphine oxides, such as tris(tert-butyl)phosphine (2), phospholene 5 and phospholane 6 , where the weaker $\mathrm{P}=\mathrm{O}$ bond are more easily reduced by PMHS, but also where the end product is easily recovered and not degraded under the rather harsh reaction conditions. To our delight, this was also the case for the reduction of the cage-like PTA $(\mathrm{O})$, the product of the oxidation at the P atom of PTA, an increasingly studied water-soluble, small cone angle adamantyl phosphine [16,17]. 
Good results were also obtained with the long-chain, lipophilic tris(n-trioctyl)phosphine oxide (4), which could be reduced efficiently running the reactions for $7 \mathrm{~h}$ at $200{ }^{\circ} \mathrm{C}$, albeit in the presence of higher amounts of PMHS (15 equiv.).

In the case of less temperature-stable substrates, such as tricyclohexylphosphine oxide (3), only moderate conversions could be achieved after $2 \mathrm{~h}$ at $250{ }^{\circ} \mathrm{C}$. For this substrate, it was not possible to run the tests for longer periods as prolonged heating led to degradation of the product, forming a number of unidentified by-products. On the other hand, lowering the temperature to $200{ }^{\circ} \mathrm{C}$ did not afford any significant conversion, most likely due to competition between the kinetics of reduction and decomposition.

Finally, an example of water-soluble charged phosphine oxide, namely $\mathbf{8}$, was studied, however evidence was obtained that this substrate could not be reduced, as decomposition occurred in all cases. This was most likely due to the difficulty of melting the substrate in the reducing polymer, thus prohibiting the formation of interactions between the two reagents, followed by degradation of the unreacted substrate under prolonged heating at high temperatures.

\section{Materials and Methods}

\subsection{Methods and Substrates}

PMHS was purchased from commercial suppliers and used as received. Substrates 1-4 and 7 were obtained by oxidation of the corresponding commercially available phosphines according to known literature procedures [24], generally using $\mathrm{H}_{2} \mathrm{O}_{2}$ (35\% in water) with some modifications and notes described as follows. Compound $\mathbf{6}$ was synthesized according to literature procedure starting from commercially available 5 [25].

\subsubsection{Synthesis of 3}

The synthesis of 3 was performed as reported [26], obtaining the oxide in $61 \%$ yield (96\% pure based on ${ }^{31} \mathrm{P}\left\{{ }^{1} \mathrm{H}\right\}$ NMR spectroscopy, $\left.\delta_{\mathrm{P}} 52.3 \mathrm{ppm}, \mathrm{CDCl}_{3}\right)$.

\subsubsection{Synthesis of 8}

As described in literature [27], oxidation of mPTA with $\mathrm{H}_{2} \mathrm{O}_{2}$ does not proceed to give the corresponding oxide. Compound 8 was synthesized by reacting PTA $(\mathrm{O})$ with methyl iodide (8: $\left.{ }^{31} \mathrm{P}\left\{{ }^{1} \mathrm{H}\right\} \mathrm{NMR}, \delta_{\mathrm{P}}-1.5 \mathrm{ppm}, \mathrm{D}_{2} \mathrm{O}\right)[28]$.

\subsection{Reduction Protocol}

As a standard procedure, the substrate and PMHS were mixed without any additional solvent in a Schlenk tube under a protective nitrogen atmosphere and heated in a sand bath to the desired temperature. Generally, a gel-like material was obtained at the end of the reaction, which was extracted with dichloromethane. After simple filtration of the remaining polymeric material on either celite or silica, the solution was analyzed by ${ }^{31} \mathrm{P}$ NMR spectroscopy, the chemical shift values were compared to pure isolated compounds and the yield determined by relative signal integration, using a long relaxation time for accurate integration.

Detailed Procedure for the Reduction of 1

The amount of $1.0 \mathrm{~g}$ of $\mathbf{1}$ ( $3.6 \mathrm{mmol}, 1.0$ equiv.) was added to a Schlenk flask and placed under a nitrogen atmosphere. Subsequently, $1.1 \mathrm{~mL}$ of PMHS (approx. $18 \mathrm{mmol}$ of Si-H bonds, 5 equiv.) was added, and the mixture was heated at $250{ }^{\circ} \mathrm{C}$. After completion of the reaction, the mixture was cooled down, dissolved in dichloromethane and filtered over a $2 \mathrm{~cm}$ silica gel pad. The clear solution was then dried under vacuum to afford $\mathrm{PPh}_{3}$ in $84 \%$ isolated yield. For the kinetic study, a sample was taken from the reaction mixture with a pipette every $30 \mathrm{~min}$, dissolved in dichloromethane and the ratio of 1 to $\mathrm{PPh}_{3}$ was analyzed by ${ }^{31} \mathrm{P}\left\{{ }^{1} \mathrm{H}\right\} \mathrm{NMR}$. 


\section{Conclusions}

The method for phosphine oxide reduction presented herein has several advantages. It uses a cheap and easily accessible reagent, namely PMHS, which is a by-product of the silicon industry. Moreover, the reaction proceeds without solvent, and only requires an extraction after completion as an easy and fast purification step. The results demonstrated that a number of industrially important phosphines can be obtained by reduction of their oxide counterparts with this protocol. Mandatory conditions for efficient reductions are the possibility to melt the phosphine oxides in PMHS without degradation, and a good stability of the corresponding phosphines at the necessary reaction temperature, usually in the range $200-250{ }^{\circ} \mathrm{C}$.

Acknowledgments: We thank the European Union (Marie Curie ITN SusPhos, Grant Agreement No. 317404) for financial support and Chemconserve BV for fruitful discussions.

Author Contributions: The experiments where performed by Emmanuel Nicolas, Antonella Guerriero and Volodymyr Lyaskovskyy, who were supervised by Maurizio Peruzzini, Koop Lammertsma, Luca Gonsalvi and J. Chris Slootweg. Luca Gonsalvi and J. Chris Slootweg conceived the experiments and wrote the paper.

Conflicts of Interest: The authors declare no conflict of interest.

\section{References}

1. Sheldon, R.A. The E Factor: Fifteen years on. Green Chem. 2007, 9, 1273-1283. [CrossRef]

2. Withers, P.J.A.; Elser, J.J.; Hilton, J.; Ohtake, H.; Schipper, W.J.; van Dijk, K.C. Greening the global phosphorus cycle: How green chemistry can help achieve planetary P sustainability. Green Chem. 2015, 17, 2087-2099. [CrossRef]

3. Kamer, P.C.J.; Van Leeuwen, P.W.N.M. (Eds.) Phosphorus(III) Ligands in Homogeneous Catalysis: Design and Synthesis; John Wiley and Sons Ltd.: New York, NY, USA, 2012.

4. Peruzzini, M.; Gonsalvi, L. (Eds.) Phosphorus Compounds: Advanced Tools in Catalysis and Material Sciences, 1st ed.; Springer: London, UK, 2011; Volume 37.

5. Johnson, A.W. Ylides and Imines of Phosphorus; Wiley: New York, NY, USA, 1993.

6. Cornils, B.; Hermann, W.A. (Eds.) Aqueous-Phase Organometallic Catalysis: Concepts and Applications, 2nd ed.; Wiley-VCH Verlag: Heidelberg, Germany, 2005.

7. Herault, D.; Nguyen, D.H.; Nuel, D.; Buono, G. Reduction of secondary and tertiary phosphine oxides to phosphines. Chem. Soc. Rev. 2015, 44, 2508-2528. [CrossRef] [PubMed]

8. Fritzsche, H.; Hasserodt, U.; Korte, F.; Friese, G.; Adrian, K.; Arenz, H.J. Reduktion organischer Verbindungen des fünfwertigen Phosphors zu Phosphinen, I. Reduktion tertiärer Phosphinoxyde zu tertiären Phosphinen mit Silanen. Chem. Ber. 1964, 97, 1988-1993. [CrossRef]

9. Shell Internationale Research Maatschappij N.V. te 's-Gravenhage. Werkwijze ter Bereiding van Fosfinen. Dutch Patent NL295914A, May 1965.

10. Fritzsche, H.; Hasserodt, U.; Korte, F. Verfahren zur Herstellung von Tertiaeren Phosphinen. German Patent DE1203773B, October 1965.

11. Keglevich, G.; Kovács, T.; Csatlós, F. The Deoxygenation of Phosphine Oxide under Green Chemical Conditions. Heteroat. Chem. 2015, 26, 199-205. [CrossRef]

12. Fritzsche, H.; Hasserodt, U.; Korte, F.; Friese, G.; Adrian, K. Reduktion organischer Verbindungen des fünfwertigen Phosphors zu Phosphinen, II. Reduktion tertiärer Phosphinoxyde zu tertiären Phosphinen mit Trichlorsilan. Chem. Ber. 1965, 98, 171-174. [CrossRef]

13. Coumbe, T.; Lawrence, N.J.; Muhammad, F. Titanium(IV) catalysis in the reduction of phosphine oxides. Tetrahedron Lett. 1994, 35, 625-628. [CrossRef]

14. Berthod, M.; Favre-Reguillon, A.; Mohamad, J.; Mignani, G.; Docherty, G.; Lemaire, M. A Catalytic Method for the Reduction of Secondary and Tertiary Phosphine Oxides. Synlett 2007, 1545-1548. [CrossRef]

15. Li, Y.; Das, S.; Zhou, S.; Junge, K.; Beller, M. General and Selective Copper-Catalyzed Reduction of Tertiary and Secondary Phosphine Oxides: Convenient Synthesis of Phosphines. J. Am. Chem. Soc. 2012, 134, 9727-9732. [CrossRef] [PubMed]

16. Li, Y.; Lu, L.Q.; Das, S.; Pisiewicz, S.; Junge, K.; Beller, M. Highly Chemoselective Metal-Free Reduction of Phosphine Oxides to Phosphines. J. Am. Chem. Soc. 2012, 134, 18325-18329. [CrossRef] [PubMed] 
17. Schirmer, M.-L.; Jopp, S.; Holz, J.; Spannenberg, A.; Werner, T. Organocatalyzed Reduction of Tertiary Phosphine Oxides. Adv. Synth. Catal. 2016, 358, 26-29. [CrossRef]

18. Phillips, A.D.; Gonsalvi, L.; Romerosa, A.; Vizza, F.; Peruzzini, M. Coordination chemistry of 1,3,5-Triaza-7-phosphaadamantane (PTA): Transition metal complexes and related catalytic, medicinal and photo-luminescent applications. Coord. Chem. Rev. 2004, 248, 955-993. [CrossRef]

19. Bravo, J.; Bolaño, S.; Gonsalvi, L.; Peruzzini, M. Coordination chemistry of 1,3,5-Triaza-7phosphaadamantane (PTA) and derivatives. Part II. The quest for tailored ligands, complexes and related applications. Coord. Chem. Rev. 2010, 254, 555-607. [CrossRef]

20. Carenco, S.; Portehault, D.; Boissiere, C.; Mézailles, N.; Sanchez, C. Nanoscaled Metal Borides and Phosphides: Recent Developments and Perspectives. Chem. Rev. 2013, 113, 7981-8065. [CrossRef] [PubMed]

21. Watson, E.; Rickelton, W. A Review of the Industrial and Recent Potential Applications of Trioctylphosphine Oxide. Solvent Extr. Ion Exch. 1992, 10, 879-889. [CrossRef]

22. O’Brien, C.J.; Tellez, J.L.; Nixon, Z.S.; Kang, L.J.; Carter, A.L.; Kunkel, S.R.; Przeworski, K.C.; Chass, G.A. Recycling the Waste: The Development of a Catalytic Wittig Reaction. Angew. Chem. Int. Ed. 2009, 48, 6836-6839. [CrossRef] [PubMed]

23. Schirmer, M.-L.; Adomeit, S.; Spannenberg, A.; Werner, T. Novel Base-Free Catalytic Wittig Reaction for the Synthesis of Highly Functionalized Alkenes. Chem. Eur. J. 2016, 22, 2458-2465. [CrossRef] [PubMed]

24. Hilliard, C.R.; Bhuvanesh, N.; Gladysz, J.A.; Blümel, J. Synthesis, purification, and characterization of phosphine oxides and their hydrogen peroxide adducts. Dalton Trans. 2012, 41, 1742-1754. [CrossRef] [PubMed]

25. Hunter, A.P.; Lees, A.M.J.; Platt, A.W.G. Synthesis, structures and mass spectrometry of lanthanide nitrate complexes with tricyclohexylphosphine oxide. Polyhedron 2007, 26, 4865-4876. [CrossRef]

26. O’Brien, C.J.; Nixon, Z.S.; Holohan, A.J.; Kunkel, S.R.; Tellez, J.L.; Doonan, B.J.; Coyle, E.E.; Lavigne, F.; Kang, L.J.; Przeworski, K.C. Part I: The Development of the Catalytic Wittig Reaction. Chem. Eur. J. 2013, 19, 15281-15289. [CrossRef] [PubMed]

27. Daigle, D.J.; Pepperman, A.B. Chemical proof for the preferred nitrogen quarternization in 1,3,5-triaza-7phosphaadamantane. J. Heterocycl. Chem. 1975, 12, 579-580. [CrossRef]

28. Daigle, D.J. 1,3,5-Triaza-7-Phosphatricyclo[3.3.1.1 3,7]Decane and Derivatives. Inorg. Synth. 1998, 32, 40-45.

(C) 2016 by the authors; licensee MDPI, Basel, Switzerland. This article is an open access article distributed under the terms and conditions of the Creative Commons Attribution (CC-BY) license (http://creativecommons.org/licenses/by/4.0/). 